\title{
Beyoncé e a construção da imagem de uma feminista negra ${ }^{1}$
}

Isabela Carias Pereira

Pontifícia Universidade Católica do Rio de Janeiro - PUC-Rio

Departamento de Comunicação Social - Bacharelado em Publicidade

\section{Resumo}

Este trabalho investiga posicionamentos feministas e questões raciais presentes nos álbuns visuais da artista Beyoncé, a fim de identificar de que maneira essas temáticas se desenvolvem no período de 2013 a 2020. Para apurar os detalhes de maneira mais qualitativa, fez-se a seleção de um videoclipe em cada álbum, nos quais são tangenciados, de maneira mais evidente, os dois principais temas da análise. Foram consideradas as letras das canções e aspectos estéticos visuais presentes nos clipes. Em complementariedade, também serão analisadas as interpretações externas desse conjunto, como a repercussão dos álbuns.

Palavras-chave: Beyoncé; Feminismo; Feminismo Negro; Racismo.

\section{Introdução}

A partir do caso da cantora Beyoncé, o presente artigo tem como objetivo entender de que forma seus trabalhos contribuíram para a construção - ou desconstrução - da imagem de mulher, feminista e negra. Desde 2013, a artista fala abertamente sobre ser feminista e tem explorado cada vez mais o feminismo negro em suas obras, o que gerou alinhamentos, a seu favor e contra, de influentes escritoras feministas, como bell hooks.

A metodologia tem como prioridade a análise dos álbuns visuais BEYONCÉ, Lemonade e Black is King, levando em consideração elementos de forma e conteúdo, como letras e aspectos visuais, e repercussão externa, como críticas da mídia e de autoras feministas. De cada obra, foi selecionado um videoclipe que pudesse representar o álbum inteiro em razão da temática principal sobre feminismo negro. Portanto, em BEYONCÉ, Flawless; em Lemonade, Formation; e em Black Is King, Brown Skin Girl. A estratégia metodológica inclui pesquisa bibliográfica sobre feminismo negro, além de alguns trabalhos acadêmicos que discutem o universo do feminismo em relação a Beyoncé.

\footnotetext{
${ }^{1}$ Derivado da monografia de graduação em Publicidade e Propaganda, orientada pela professora Bárbara Assumpção e entregue em junho de 2021.
} 


\section{Alguém não sabe quem é Beyoncé?}

Beyoncé Giselle Knowles-Carter nasceu no dia 4 de setembro de 1981 em Houston, Texas. Seus talentos foram descobertos ainda na infância e, aos 9 anos, Beyoncé entrou em uma girlband ${ }^{2}$ de nome Girls Tyme. Em 1997, agora com o nome de Destiny's Child, o grupo tornou-se mundialmente famoso. Beyoncé começa a sua carreira solo em 2003 e, em 2011, assume completamente a sua vida profissional, que até então contava com seu pai como empresário.

Eu raramente me sentia representada em filmes, moda e outras mídias. Depois de ter uma filha, fiz minha missão de usar minha arte para mostrar o estilo, a elegância e a atração em homens e mulheres de cor. (Beyoncé, em entrevista à revista ELLE, 2019)

Beyoncé reafirma a todo tempo a importância da sua família e de tornar-se uma boa referência para seus filhos. Blue, a filha primogênita, nasceu em 2012, e uma narrativa diferente é percebida a partir desse momento nas canções de Beyoncé. Desde 2013, Beyoncé aposta no formato conhecido como álbum visual. De acordo com Harrison (2014, p. 2), "o álbum visual é um meio híbrido entre videoclipe e cinema; como o videoclipe, ele promove um álbum musical, e como o filme, é concebido como uma obra artística". Sua construção apresenta maior duração que um clipe e costuma articular apenas uma unidade temática.

Em 2013, Beyoncé lança seu álbum visual homônimo, em que fala explicitamente pela primeira vez sobre feminismo. Na canção ***Flawless, a artista mostra esse posicionamento com um trecho do discurso "Sejamos Todos Feministas", ${ }^{3}$ proferido pela escritora feminista Chimamanda Ngozi Adichie no TEDxEuston, em 2012.

Lemonade, de 2016, é o segundo álbum visual de Beyoncé, marcado por uma profundidade artística e por levantar um debate racial. A temática principal do álbum é sobre o impacto da estrutura racista no amor entre pessoas negras.

Beyoncé é feminista, como deixou bem claro no seu álbum autointitulado de 2013. Mas para mulheres negras, o feminismo pode, às vezes, ser algo muito desafiador, pois elas lutam pelos direitos das mulheres enquanto apoiam os homens negros na luta pelo racismo. Muitas vezes as mulheres negras se veem tendo que escolher entre ser politicamente mulheres ou politicamente negras.(SANTIAGO, 2020)

\footnotetext{
${ }^{2}$ Banda musical composta apenas por meninas.
}

${ }^{3}$ No original: We Should All Be Feminists. 
A construção do olhar pelo viés da negritude é um percurso longo e complexo. Antes de lançar o álbum, Beyoncé já se mostrava disposta a opinar sobre temas como o uso policial contra jovens negros e a força e empoderamento da mulher negra. Porém, este é o primeiro álbum em que a artista discute sobre esses assuntos.

Black Is King, de 2020, foi o último lançamento da artista. O filme é extremamente ligado à África, mas não faz alusão a nenhum país específico e se encaixa no movimento afrofuturista. Segundo a pesquisadora e crítica de cinema Kênia Freitas, o movimento "abrange diversas narrativas de ficção especulativa - aquela que se propõe a especular sobre o futuro e 0 passado -, sempre da perspectiva negra, tanto africana quanto diaspórica". ${ }^{4}$

Quando, mesmo em um futuro imaginário - um espaço em que a mente pode ir além da Via Láctea para visualizar rotineiras viagens no tempo, animais espaciais fofos, macacos falantes e máquinas do tempo pessoas não conseguem imaginar uma pessoa não-descendente de europeu mil anos no futuro, uma história cósmica deve ser criada. (WOMACK, 2013, p. 11-12)

É possível entender que BEYONCÉ, de 2013, e Lemonade, de 2016, com todas as questões levantadas, abriram portas para que Black Is King, de 2020, pudesse existir. A última obra trata com uma profundidade ainda maior questões como ancestralidade e de empoderamento feminino negro.

Para o feminismo negro, [empoderamento] possui um significado coletivo. Trata-se de empoderar a si e aos outros e colocar as mulheres como sujeitos ativos da mudança. [...] Quando uma mulher se empodera, tem condições de empoderar outras. (RIBEIRO, 2018, p. 135)

Desde 2013, com o seu primeiro álbum visual, as obras de Beyoncé ganham um sentido mais amplo e profundo e, no decorrer dos anos, tocam gradativamente em aspectos do feminismo e da valorização da mulher, e ao mesmo tempo da negritude e ancestralidade.

${ }^{4}$ Conforme matéria veiculada em Socialismo Criativo. Disponível em:

<https://www.socialismocriativo.com.br/rexistencia-o-afrofuturismo-imagina-futuros-possiveis-com-olhar-sobre-aancestralidade-e-o-

presente/\# : : :text=K\%C3\%AAnia\%20resume\%20que\%200\%20afrofuturismo,\%2C\%20tanto\%20africana\%20quanto \%20diasp\%C3\%B3rica\%E2\%80\%9D>. Acesso em 30, abril de 2021. 


\section{3. Álbuns visuais em análise a partir de videoclipes}

Para Thiago Soares (apud VECCHIA, 2017), quando falamos na associação canção e videoclipe, é necessário um percurso analítico próprio para compreender a totalidade dos elementos estéticos e características presentes em ambos os produtos. Nesse sentido, a canção seria antecessora à construção de imagens encontrada no videoclipe. Amparadas por essa constatação, todas as análises começarão a partir da letra e, depois, das imagens. Todas as considerações devem orientar ao entendimento sobre a carreira de Beyoncé no que diz respeito à continuidade das abordagens sobre feminismo e feminismo negro no decorrer do tempo.

\section{1***Flawless}

O álbum BEYONCÉ é muito experimental, tanto em relação ao processo de criação quanto em relação ao seu lançamento. Em uma indústria musical tomada por singles, a artista escolhe o formato inusitado do álbum visual e faz um lançamento surpresa.

Agora as pessoas só escutam alguns segundos da música em seus iPods. Não investem efetivamente no álbum inteiro. É tudo sobre o single e hype. E muita coisa fica entre a música, o artista e os fãs. Eu sentia, "não quero que ninguém dê a mensagem quando o meu disco sair. Eu só quero que isso saia quando estiver pronto e de mim para os meus fãs". Falei para a minha equipe que queria gravar um vídeo para cada música e lançá-los juntos ao mesmo tempo. Todos pensaram que eu era louca, mas estamos fazendo isso. (BEYONCÉ, "Self-Titled": Part 1 ..., 2013. Tradução nossa)

Quando a música começa, as batidas e vozes são constantes. Em uma mistura dos gêneros hip-hop e pop, a letra é bastante repetitiva e diz frases como "não pense que sou apenas sua pequena esposa" 5 e "respeitem isso, curvem-se vadias". ${ }^{6}$ Essa introdução da música é, na verdade, uma outra canção, de nome Bow Down. Beyoncé (BEYONCÉ, "Self-Titled": Part 2..., 2013), em um dos vídeos de divulgação do álbum, reflete sobre o encontro dessas duas canções. Ela diz gostar da agressividade de Bow Down com a atitude de ***Flawless.

Não há muita variação até o trecho de Chimamanda Ngozi Adichie surgir. Vivendo desde os 19 anos nos Estados Unidos, a escritora nigeriana é conhecida por suas obras sobre igualdade de gênero. O sample de Chimamanda veio da palestra "Sejamos Todos Feministas", posteriormente editada em livro.

\footnotetext{
${ }^{5}$ No original: Don't think I'm just his little wife.

${ }^{6}$ No original: Respect that, bow down bitches.
} 
Ensinamos as meninas a se encolherem/ Para se tornarem ainda menores/ Dizemos para meninas: "Você pode ter ambição, mas não muita/ Você deve ansiar por ser bem-sucedida/ Mas não tão bemsucedida/ Caso contrário, você vai ameaçar o homem"/ Porque sou do sexo feminino/ Esperam que eu almeje o casamento/ Esperam que eu faça as escolhas da minha vida/ Sempre tendo em mente que/ O casamento é o mais importante/ O casamento pode ser uma fonte de alegria, amor e apoio mútuo/ Mas por que ensinamos as meninas a ansiar pelo casamento/ E não ensinamos a mesma coisa aos meninos?/ Criamos meninas para serem concorrentes / Não para empregos ou para conquistas/ Que eu acho que pode ser uma coisa boa/ Mas para a atenção dos homens/ Ensinamos as meninas que elas não podem ser seres sexuais/ Da mesma forma que os meninos são/ Feminista: a pessoa que acredita na igualdade social, política e econômica entre os sexos. (ADICHIE; BEYONCÉ, 2013. Tradução nossa)

No momento desse discurso de duração considerável, a batida pesada cessa e podemos escutar uma voz feminina aveludada cantarolando ao fundo, quase lírica, com uma dramaticidade que envolve o que é falado. Depois, escutamos o trecho em que Beyoncé canta como todas as mulheres são perfeitas.

O P\&B está presente em todo videoclipe de ***Flawless, com exceção do início e do fim. Ainda criança, Beyoncé e a girlband Girls Tyme participaram do programa de TV Star Search, uma espécie de show de talentos em que grupos musicais competiam entre si. Em cores, o antigo vídeo mostra, no início do videoclipe, o apresentador do programa anunciando as meninas para a competição. Ao final do videoclipe, o apresentador anuncia os vencedores: um grupo musical de homens brancos adultos. Os rostos das crianças de Girls Tyme aparecem, intactos, com sorrisos estritamente profissionais, sem demonstrar frustração alguma em perder.

O início e fim parecem explicar o motivo da existência do que está no meio: o videoclipe de ***Flawless. É no mínimo injusta a competição na mesma categoria entre crianças e adultos. Ademais, é interessante perceber que todas as meninas do grupo Girls Tyme são negras, enquanto os integrantes do grupo de adultos são homens brancos. Ainda assim, não há nada na canção em si que articule sobre questões raciais.

A quebra entre o trecho e o início do clipe se dá por um efeito que se assemelha a uma televisão desligando. O P\&B de ${ }^{* * * F l a w l e s s ~ n a ̃ o ~ t e m ~ o ~ o b j e t i v o ~ d e ~ p a r e c e r ~ v i n t a g e, ~ a t e ́ ~ p o r q u e ~}$ os trechos do programa de TV são muito mais antigos e são coloridos, mas sim, um preto e branco contemporâneo e moderno, em um clipe que explora outros aspectos que não a cor.

Outra característica presente em todo clipe é a referência ao movimento punk: uma energia caótica, com pessoas vestindo meias-calças rasgadas, correntes e maquiagens pesadas. A 
todo momento, Beyoncé e os outros personagens em cena olham para a câmera de uma forma intimidadora. No trecho de Chimamanda, o clipe fica em câmera lenta. Há uma colisão intencional entre as pessoas, fazendo alusão a uma roda-punk, conhecida como mosh.

Figura 1. Beyoncé e outros personagens na encenação de mosh.

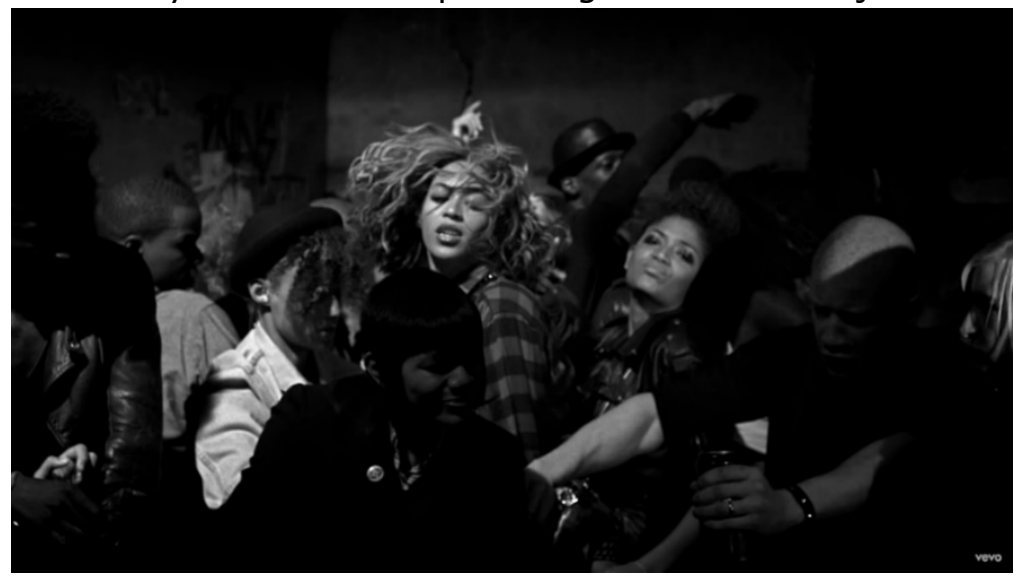

Fonte: YouTube (2021).

Todos esses elementos fazem parte de um movimento musical e cultural da qual a artista não faz parte. O punk rock surgiu na década de 1970, em oposição ao rock progressivo de muito sucesso na época. ${ }^{7} \mathrm{Ou}$ seja, não é esperado que Beyoncé, grande nome da música pop e mainstream, esteja associada a um movimento de contracultura e, em sua origem, anticapitalista.

É importante relembrar que esse é o primeiro momento que o feminismo fica explícito em uma obra da artista. Uma carreira de nível global pode ampliar qualquer discussão em várias escalas e talvez, nesse momento, essa representação tenha sido o suficiente para que as obras seguintes fizessem sentido.

\subsection{Formation}

Lemonade, de 2016, é o segundo álbum visual de Beyoncé. Com cerca de 65 minutos de duração, a obra é dividida em onze capítulos inspirados pelo modelo cinco estágios do luto, ou modelo Kübler-Ross, proposto pela psiquiatra suíça Elisabeth Kübler-Ross. O modelo sugere que quando alguém recebe uma notícia ruim em relação ao seu prognóstico, sua continuidade de vida ou saúde, decorrem cinco estágios do luto: negação, raiva, barganha, depressão e aceitação. No caso de Beyoncé, a notícia ruim foi uma pressuposta traição de seu marido.

\footnotetext{
${ }^{7}$ Conforme artigo veiculado em Super Interessante. Disponível em: <https://super.abril.com.br/mundo-estranho/oque-foi-o-movimento-punk/>. Acessoem 29, maio de 2021.
} 
Portanto, cada um dos capítulos traz diferentes aspectos de um relacionamento conturbado, até o momento do perdão.

Ao contrário de BEYONCÉ, em que cada clipe pode contar uma história separadamente, o álbum visual Lemonade conta uma história única, e a ligação entre as canções se dá por poemas da poetisa britânica Warsan Shire, recitados por Beyoncé em voice-over. ${ }^{8}$ Cada um dos onze capítulos constrói a jornada de uma mulher negra, seu autoconhecimento e a quebra de uma estrutura racista de famílias negras, que muitas vezes são construídas sem a presença masculina.

Você me lembra meu pai, um mágico... Capaz de existir em dois lugares ao mesmo tempo. Na tradição dos homens em meu sangue, você chega em casa às $3 \mathrm{~h}$ da manhã e mente para mim. O que você está escondendo? $O$ passado e o futuro se fundem para nos encontrar aqui. Que sorte. Que merda de maldição. (Trecho do poema durante capítulo "Intuição". BEYONCÉ, 2016)

Formation foi lançado como single, antes do lançamento do álbum. Na construção do filme, o videoclipe aparece depois dos créditos, ou seja, não está inserido em nenhum dos capítulos. Isso faz parecer com que Formation seja uma espécie de resumo de tudo que foi mostrado.

Papai é do Alabama, mamãe Louisiana/ Você mistura esse negro com aquela crioula e faz uma texana revoltosa/ Gosto do cabelo do meu bebê, com baby hair ${ }^{9}$ e afro/ Eu gosto do meu nariz negro com narinas Jackson Five/ Ganharam todo esse dinheiro, mas eles nunca tiraram meu país de mim/, Tenho molho picante em minha bolsa, swag. (Formation. BEYONCÉ, 2016. Tradução nossa)

No início da música, são relatadas relações familiares, tanto olhando para o passado, sobre a origem dos seus pais, tanto olhando para o futuro, em uma exaltação do cabelo de sua filha. Beyoncé cita os Jackson Five, grupo de Michael Jackson e seus irmãos, sobre o orgulho que tem de seus traços e narizes negroides.

No refrão, Beyoncé diz que é uma estrela e "arrasa", e este último chamado cresce no decorrer da canção. Depois de dizer algumas vezes que arrasa, o substantivo passa a ser no plural: nós arrasamos. Junto a isso, escutamos a famosa frase "Okay ladies, now let's get in

\footnotetext{
${ }^{8}$ Voice-over é uma técnica em que vozes são gravadas sobre a faixa de áudio original, portanto, em segundo plano. ${ }^{9}$ Baby hair é uma espécie de penteado com cabelos novos, que nascem na linha capilar em volta do rosto e costumam ser curtos e rebeldes. Originou-se em mulheres afro-americanas e latinas, em um recurso criativo para organizar esses fios.
} 
formation". ${ }^{10}$ Beyoncé entende que, para acabar com a violência oriunda da supremacia branca, as mulheres devem lutar de forma organizada, assim como aconteceu no movimento Panteras Negras.

Os Panteras Negras surgiram como um grupo que defendia a resistência armada contra a opressão dos negros. Fundado em outubro de 1966, o grupo nasceu prometendo patrulhar os bairros de maioria negra para proteger seus moradores contra a violência policial. [...] Hoje, o legado dos Panteras Negras é avaliado como fundamental na conquista de direitos pelos negros americanos, e o nome do grupo segue como grande símbolo da luta contra o racismo no mundo todo. (NAVARRO, 2019)

Uma das lutas do movimento feminista é a independência da mulher na esfera privada e pública. Ao questionar as categorias estabelecidas na sociedade sobre os gêneros, como a submissão das mulheres aos seus maridos, a lógica da família "tradicional" vem sendo quebrada. Porém, consciente ou inconscientemente, algumas mulheres continuam aderindo a este modelo, enxergando-o como o único possível. Beyoncé se entende publicamente feminista desde 2013, como vimos na análise de ***Flawless, mas a construção de sua narrativa é sempre atravessada por um relacionamento heteronormativo e muitas de suas ações nas músicas têm o objetivo de satisfazer um homem. Em uma entrevista de junho de 2021, Chimamanda Ngozi Adichie reconheceu a dificuldade de existir um feminismo "puro", capaz de erradicar todas as percepções pessoais machistas.

Nem todos no mundo são feministas, e histórias precisam ser honestas, acho. A narrativa precisa ser honesta. Eu me interesso por seres humanos, e os seres humanos são falhos, confusos, maravilhosos e terríveis, são todas essas coisas. [...] Nós não somos organizados, não cabemos em bolsinhos. Sou feminista, mas posso dizer que não sou "pura" no meu feminismo. (Roda Viva com Chimamanda Ngozi Adichie. TV CULTURA, 2021)

Logo no início do clipe, vemos Beyoncé por cima de uma viatura policial em uma paisagem completamente inundada, com casas submersas e objetos flutuantes. Essa cena faz referência ao furacão Katrina que, em 2005, atingiu potência máxima no estado de Louisiana, principalmente na cidade de Nova Orleans. A passagem do furacão Katrina deixou partes da cidade completamente alagadas, cidade em que $60 \%$ da população é negra e a taxa de pobreza entre a população negra é o triplo da verificada entre a população branca. ${ }^{11}$

\footnotetext{
${ }^{10} \mathrm{Em}$ português: "Certo senhoras, agora vamos entrar em formação".

${ }^{11}$ Conforme notícia veiculada em BBC News Brasil. Disponível em: <https://www.bbc.com/portuguese/internacional53944395>. Acesso em 14, junho de 2021.
} 
O sul dos Estados Unidos, historicamente, foi palco da escravidão em massa do povo africano e, em seguida, de políticas para segregação racial. Por isso, Nova Orleans torna-se um ponto chave para a história contada. Ao mesmo tempo que Beyoncé flutua em cima de um carro de polícia com o símbolo New Orleans Police ${ }^{12}$ em destaque, uma voz questiona o que aconteceu em Nova Orleans.

Logo em seguida, escutamos a conhecida frase "Bitch, I'm backby popular demand", ${ }^{13}$ enquanto aparecem capturas da comunidade negra norte-americana exercendo atividades diversas. A voz é de um YouTuber chamado Messy Mya, um homem gay e negro assassinado em 2019 quando voltava de um chá de bebê. Beyoncé aparece com um grupo de homens negros vestidos de maneira formal e tradicional. Ela veste um chapéu grande, que consegue cobrir seus olhos. Todos estão de preto. O figurino lembra os utilizados em cortejos fúnebres de Nova Orleans e, inclusive, uma das cenas posteriores no clipe mostra um desses funerais. Observando os aspectos da polícia, do assassinato de um jovem negro e de um cortejo funeral, é possível entender que Beyoncé refere-se ao genocídio negro e à violência policial.

Outras cenas importantes são as que Beyoncé aparece, sozinha ou acompanhada de figurantes ou dançarinas, vestida com roupas de alta classe do período colonial. Estão em um contexto de realeza, como se agora fossem donas da casa-grande, e não escravas da senzala. Todos os quadros presentes nas paredes dessa grande mansão são de mulheres negras e suas famílias.

Figura 2. Beyoncé e figurantes com figurinos diversos em um cenário que remonta século XVIII.

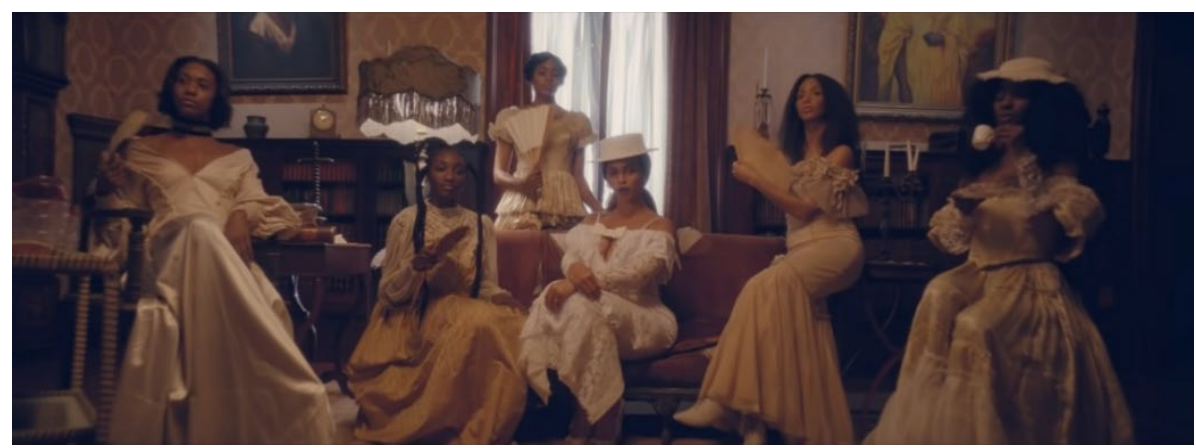

Fonte: YouTube (2021).

\footnotetext{
${ }^{12} \mathrm{Em}$ português: "Polícia de Nova Orleans".

${ }^{13} \mathrm{Em}$ português: "Vadia, estou de volta por demanda popular".
} 
Seguindo o caminho de ressignificação e de uma certa reparação histórica, Beyoncé aparece com dançarinas negras dentro de uma piscina vazia. Nos séculos XIX e XX, eram vigentes leis de segregação racial nos Estados Unidos.

O termo "Jim Crow", nascido de uma música popular, referia-se a toda lei (foram dezenas) que seguisse o princípio "separados, mas iguais", estabelecendo afastamento entre negros e brancos nos trens, estações ferroviárias, cais, hotéis, barbearias, restaurantes, teatros, entre outros. Em 1885, a maior parte das escolas sulistas também foram divididas em instituições para brancos e outras para negros. Houve "leis Jim Crow" por todo o sul. Apenas nas décadas de 1950 e 1960 a suprema Corte derrubaria a ideia de "separados, mas iguais". (KARNAL, 2007)

As piscinas norte-americanas foram palco de grandes tensões raciais, uma vez que existiam piscinas para pessoas brancas e outras para pretas. Com o movimento dos direitos civis para acabar com a segregação nos Estados Unidos, muitas pessoas negras em protesto começaram a entrar em piscinas de pessoas brancas e, por isso, eram atacadas.

Em uma das cenas, Beyoncé e dançarinas aparecem em um estacionamento na formação de um "X". Há interpretações desse trecho que relacionam a formação com o líder Malcom $X$, ativista no combate à desigualdade social e racial nos Estados Unidos dos anos 1960. Filmada em um ângulo de cima com um efeito de gravação antigo, a cena parece gravada por uma câmera de segurança. Em uma sociedade estruturalmente racista, indivíduos de pele escura estão sempre sendo observados e, mesmo sem uma política oficial de segregação racial, correm o perigo de serem incriminados injustamente.

Na era da neutralidade racial [colorblindness], não é mais socialmente permissível usar a raça, explicitamente, como justificativa para a discriminação, a exclusão e o desprezo social. Então não a usamos. Em vez de nos servirmos de raça, usamos nosso sistema de justiça criminal para pregar nas pessoas não brancas o rótulo "criminoso" e, com isso, nos permitimos prosseguir com as mesmas práticas que supostamente teríamos deixado para trás. [...] $\mathrm{Na}$ condição de criminoso, você praticamente não terá mais direitos, e possivelmente terá menos respeito do que um homem negro vivendo no Alabama na época do Jim Crow. Nós não acabamos com as castas raciais nos Estados Unidos; nós apenas as remodelamos. (ALEXANDER, 2017, p. 35)

No combate entre policiais e pessoas negras, todos saem perdendo. Em uma das últimas cenas, Beyoncé aparece afundando junto àquela viatura policial. A artista foi muito criticada pela polícia norte-americana após o lançamento do clipe e, mais ainda, logo depois, quando fez uma performance no Super Bowl, jogo final do campeonato da NFL, principal liga de futebol americano dos Estados Unidos. Todas as suas dançarinas vestiam figurinos das Panteras 
Negras. Houve uma mobilização para o boicote à Beyoncé, com acusações de desrespeito aos policiais.

A produção foi uma das mais premiadas de toda a carreira da artista, somando mais de quinze prêmios, incluindo um Grammy na categoria de melhor videoclipe. Com diversas indicações no MTV Video Music Awards (VMA), Beyoncé foi a primeira mulher negra a receber a premiação de melhor vídeo pop. Em comparação a ***Flawless, Beyoncé aqui demonstrou-se não só feminista, mas feminista negra. Beyoncé está, nesse momento, inserida em um processo de tomada de consciência sobre seu espaço na sociedade como mulher negra. É um momento estratégico, em que sua carreira está completamente estabelecida e dificilmente ela será silenciada.

\subsection{Brown Skin Girl}

O álbum visual Black Is King, de 2020, é um longa-metragem que utiliza a trilha sonora de The Lion King: The Gift, produzida pela cantora para o remake em liveaction ${ }^{14}$ do filme $O$ Rei Leão, da Disney. Assim como Lemonade, Black Is King também utiliza a técnica de voice-over como uma forma de ligação entre uma música e outra. Desta vez, o que escutamos são trechos do filme $O$ Rei Leão, algumas reflexões de pessoas negras e da própria Beyoncé.

Beyoncé traz, nesta obra, a ideia de que antes da colonização e escravidão existiam pessoas negras no continente africano com muitas riquezas materiais e imateriais. Não há imagens de miséria, pobreza e fome; há o rompimento desse estereótipo da África. O objetivo é enaltecer o belo, a autoestima de afrodescendentes e celebrar a ancestralidade. É como se todos, em algum ponto, fossem descendentes de reis africanos. Black Is King, fazendo uma releitura do filme original, conta sobre o percurso de autoconhecimento de uma jovem criança até o momento de tornar-se rei, em um contexto contemporâneo e até futurístico.

Garota de pele marrom/ Sua pele é como pérolas/ A melhor coisa do mundo/ Nunca trocaria você por ninguém/ Cantando, garota de pele marrom/ Sua pele é como pérolas/ A melhor coisa do mundo/ Eu nunca trocaria você por mais ninguém, cantando. (Brown Skin Girl. BEYONCÉ, 2019. Tradução nossa) ${ }^{15}$

\footnotetext{
${ }^{14}$ Conforme a plataforma FilmeFeed, liveaction é "um filme baseado em uma animação, ou em quadrinhos e até em jogos de vídeo game, que ganham versões feitas por atrizes e atores de verdade." Disponível em: <https://filmefeed.telecineplay.com.br/o-que-e-live-action/p>. Acesso em 16, junho de 2021.

${ }^{15}$ No original: Brown skin girl/ Your skin just like pearls/ The best thing in the world/ Never trade you for anybody else/ Singin' brown skin girl/ Your skin just like pearls/ The best thing in the world/ I never trade you for anybody else, singin'.
} 
Com uma voz angelical e suave, Blue Ivy, filha de Beyoncé de apenas 9 anos, canta o trecho quase em a capella, acompanhada do rapper SAINt JHN e de algumas palmas. Ao final da primeira estrofe, há uma batida marcada e o rapper WizKid começa a cantar. Essa batida não é a comumente utilizada por Beyoncé. Estamos escutando uma canção afrobeats, gênero dominado por tambores com origem em boates de Gana e da Nigéria. ${ }^{16}$

WizKid canta duas estrofes e o refrão mais uma vez. É exposta uma relação heteronormativa, em que há uma exaltação da beleza e independência da mulher, mas sempre em relação ao homem. Durante os seus primeiros versos, WizKid diz: "Apenas um jeans e uma camiseta branca pura/ Ela nunca fez algo para ser a esposa de alguém, sim". ${ }^{17}$ Há, portanto, uma espécie de independência da mulher que o atrai.

Esta noite, eu posso me apaixonar/ Depende de como você me abraçar/ Estou feliz que estou me acalmando/ Não posso deixar ninguém vir e me controlar/ Continue dançando e chame isso de amor/ Ela luta, mas se apaixona aos poucos/ Se algum dia ficar em dúvida, lembre-se do que a mamãe te contou. (Brown Skin Girl. BEYONCÉ, 2019. Tradução nossa) ${ }^{18}$

Os primeiros versos cantados por Beyoncé falam sobre a representatividade na mídia de mulheres negras, principalmente as mais retintas. São citadas a modelo Naomi Campbell, a atriz Lupita Nyong'o e a cantora Kelly Rowland, esta última uma amiga antiga de Beyoncé, que também fez parte do grupo Destiny's Child: "Pose como um troféu quando a Naomi entrar/Ela precisa de um Oscar por aquela pele negra/Bonita como a Lupita, quando a câmera se aproxima/A represa arrebentou quando minha Kelly chegou" (Tradução nossa). ${ }^{19}$

Tal qual Formation, em que Beyoncé chama as mulheres para uma formação, Brown Skin Girl convoca as mulheres de "pele marrom" para uma luta. Porém, nesse caso, não é apenas contra o racismo, mas a favor do empoderamento negro.

O cinema, o teatro, a televisão, a moda, a música, a dança e todas as expressões artísticas serão ferramentas importantes para que isso seja colocado em prática e justamente por isso esse é um dos campos mais perversos em relação ao racismo atuante. Nesses lugares de trabalho imagético, somos sistematicamente excluídos, dando a ideia de que não

\footnotetext{
${ }^{16}$ Conforme notícia veiculada em Vogue. Disponível

em:<https://vogue.globo.com/lifestyle/cultura/noticia/2015/05/afrobeats-genero-renovado-e-batida-da-vez-naspistas-londrinas.html>. Acesso em 18, junho de 2021.

${ }^{17}$ No original: Just a likkle jeans and a pure white tee/ She never did forever be nobody wifey, yeah.

${ }^{18}$ No original: Tonight I might fall in love/ Dependin' on how you hold me/ I'm glad that I'm calmin' down/ Can't let no one come control me/ Keep dancin' and call it love/ She fightin', but fallin' slowly/ If ever you are in doubt, remember what mama told me.

${ }^{19}$ No original: Pose like a trophy when Naomis walk in/ She need an Oscar for that pretty dark skin / Pretty like Lupita when the cameras close in/ Drip broke the levee when my Kellys roll in.
} 
existimos enquanto seres artísticos e, portanto, portadores de estética desejável ou, ainda, somos colocados em número desproporcional em relação aos brancos e em lugares de pouca visibilidade. (BERTH, 2019, p.76)

Há um convite às mulheres negras para uma reflexão sobre suas belezas únicas: "Você tem se olhado no espelho ultimamente?/Queria que pudesse trocar de olhos comigo/Há complexidades na aparência/Mas sua pele, brilha como diamante" (Tradução nossa). ${ }^{20}$ É possível interpretar que essa complexidade diz respeito às características negroides dessas mulheres que, fazendo uma referência à Formation, têm narizes largos como os Jackson Five.

Antes de uma das últimas repetições do refrão, Beyoncé canta sobre como ser uma mulher tão gloriosa faz com que os homens apaixonem-se por você. Se, por um lado, houve um crescimento do seu posicionamento como mulher negra, houve, também, uma estagnação acerca de seu posicionamento como mulher heterossexual, que enxerga a relação heteroafetiva como única possível. Você, mulher, com toda sua glória, será o motivo de um homem se apaixonar.

Esses homens, vão se apaixonar por você e toda a sua glória/ Sua pele não é apenas escura/ Ela brilha e conta a sua história/ Continue dançando, eles não podem te controlar/ Eles assistem, todos eles te adoram/ Se alguma vez você estiver em dúvida/ Lembre-se do que mamãe te contou. (Brown Skin Girl. BEYONCÉ, 2019. Tradução nossa) ${ }^{21}$

O videoclipe de Brown Skin Girl começa com uma menina negra, de vestido azul e laço amarelo na cabeça, andando sobre folhas que caem lentamente ao chão. Escutamos Beyoncé, em um interlúdio antes da música efetivamente começar, dizendo: "Éramos beleza antes que soubessem o que era beleza". ${ }^{22}$ As cenas seguintes são um retrato muito forte do aprendizado e contato tanto com suas equivalentes quanto com pessoas mais distantes em sua árvore genealógica, como mãe, tias e avós, e a importância da troca entre as gerações.

A menina de vestido azul agora está em um cenário fechado, no que parece ser um grande salão de festas, com um palco repleto de flores dos mais diferentes tipos. Quando a câmera mostra o salão de outro ângulo, percebemos a presença de várias meninas em vestidos de debutante. Com origem na segunda metade século XVI na Europa antiga, a festa de debutante era o momento em que famílias nobres realizavam um grande baile para apresentar à

\footnotetext{
${ }^{20}$ No original: Have you looked in the mirror lately?/ Wish you could trade eyes with me/ There's complexities in complexion/ But your skin, it glow like Diamonds.

${ }^{21}$ No original: Them men, themgon' fall in love with you and all of your glory/ Your skin is not only dark, it shines and it tells your story/ Keep dancin', they can't control you, they watchin', they all adore you/ If ever you are in doubt/ Remember what mama told you.

${ }^{22}$ No original: We were beauty before they new what beauty was.
} 
sociedade suas filhas. As meninas vestem-se com roupas de gala e parecem verdadeiras princesas, o que, no contexto de Brown Skin Girl, é muito significativo. O álbum visual Black Is King teve seu lançamento na plataforma de streaming da Disney, companhia muito famosa por produzir filmes de princesas e que falhou no decorrer dos anos em não trazer representações de outros grupos étnicos não-europeus para essas personagens. Isso dificultou, de alguma forma, a criação de autoestima das meninas negras, que não se viam representadas nesse ambiente de graciosidade e esplendor.

Com figurinos sofisticados, vemos, em uma sala, Beyoncé, Blue Ivy e algumas celebridades de pele escura. Algumas debutantes também estão presentes. Apesar de celebrar mulheres famosas no clipe e na letra da canção, há um cuidado em relação à diversidade das representações de meninas e mulheres que aparecem. Não é preciso fama para reconhecer-se bonita com o seu tom de pele "marrom".

No racismo, o cabelo torna-se um fardo para as mulheres negras. Durante os anos 1960, penteados como o blackpower tornaram-se protagonistas na luta pelos direitos civis. Professora, filósofa e escritora, Angela Davis surge como um dos nomes do movimento Panteras Negras. Entre as pautas do movimento, havia a aceitação da beleza negra, e o cabelo natural fazia parte desse contexto. Angela Davis tornou-se, portanto, não só referência de luta, mas muito deste respeito advinha do seu afro, que se tornava mais uma maneira de intimidar opressores e de rejeitar a obsessão cultural pelos cabelos alisados. Não alisar os cabelos é, para os negros, um ato político.

Parecem-nos, então, muito coerentes os discursos e narrativas de enfrentamento do racismo vigente, que exaltam os cabelos como elemento de orgulho racial, pois amá-los significa cuspir de volta para a boca do sistema racista todas as ofensas, rejeições, exclusões que nos são direcionadas ao longo de toda uma vida. (BERTH, 2019, p.72)

De frente e de costas, vemos mulheres de diferentes idades com cabelos trançados. Beyoncé aparece com vários penteados típicos de países do continente africano, como tranças de pontas adornadas, oriundas do Egito. Penteados com tranças surgiram na África e tinham como objetivo separar tribos em relação a religião, idade, parentesco e outros atributos. Atualmente, algumas mulheres optam pela utilização da trança para o fim de suas transições capilares, ou seja, quando param de alisar seus cabelos e para voltar aos cabelos naturais. 
Figura3. Mulheres e meninas negras, de costas, com cabelos trançados de diferentes maneiras.

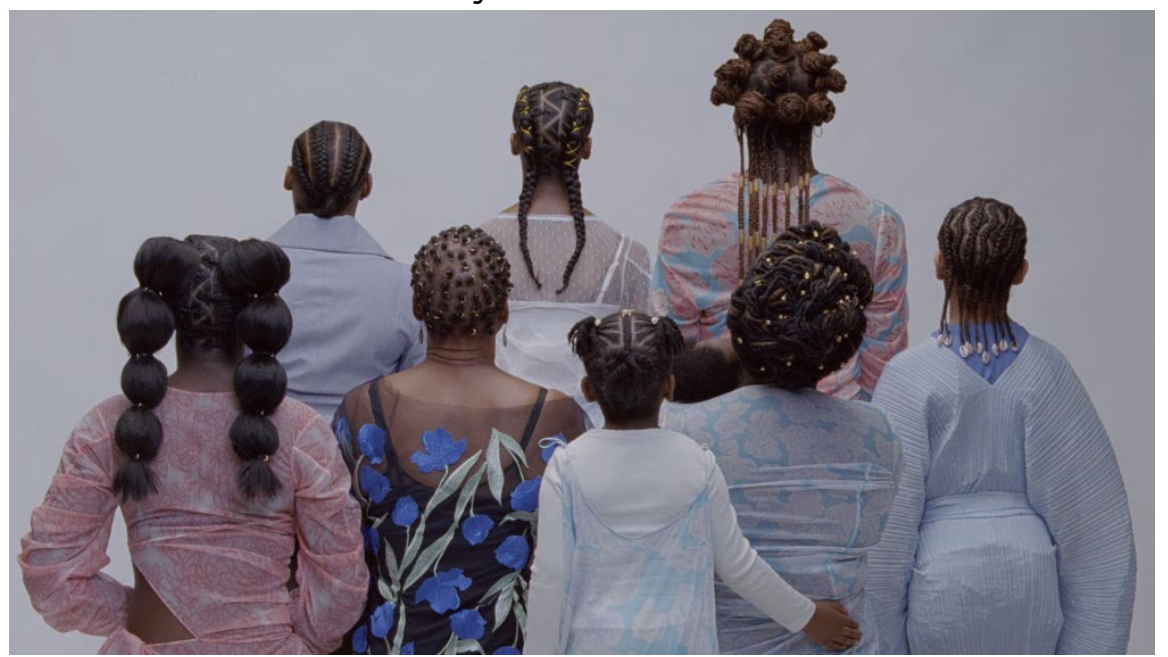

Fonte: YouTube (2021).

O álbum The Gift, trilha sonora de Black Is King, dispôs de um documentário com o processo de criação das músicas. Sobre Brown Skin Girl, Beyoncé relatou: "Foi muito importante pra mim que a música não fosse uma trilha sonora comum, mas algo que as crianças se sentissem seguras e animadas para compartilhar com seus pais, assim como os pais com seus filhos" (BEYONCÉ PRESENTS: Making The Gift, 2019. Tradução nossa). Em uma das últimas cenas, Beyoncé aparece ao lado de suas filhas e de sua mãe, Tina Knowless. Mais uma vez, é retomada a importância de celebrar a ancestralidade.

A presença de artistas africanos durante o álbum visual é de extrema relevância. Conhecidas como featuring, ou apenas feat, as parcerias musicais ampliam a visibilidade de todos os cantores envolvidos. No caso de Beyoncé, artista mundialmente conhecida, SAINt JHN e WizKid ganham evidência para além do continente africano e seus fãs. É importante dizer também que, entre os prêmios recebidos do álbum, Brown Skin Girl recebeu um Grammy na categoria de melhor clipe, elegendo Blue Ivy, filha de Beyoncé, a segunda pessoa mais jovem a conquistar essa premiação.

Uma releitura da história original abre caminho para novas interpretações e construções de imaginário, mas Beyoncé optou por manter a narrativa do homem protagonista buscando o seu destino. Brown Skin Girl também traz traços dessa dependência masculina. Uma mulher pode se sentir gloriosa sem o desejo de atrair um homem por consequência?

O trabalho para realização do álbum durou mais de um ano, e Beyoncé fez viagens para vários países da África, contando não só com o featuring, mas com diretores e produtores do 
continente. A produção audiovisual é extremamente sofisticada. Estudar a construção dessas imagens célebres e as afetações a partir delas, principalmente em mulheres negras, é entender que movimentos como esse desmontam, de alguma forma, o discurso "branco".

\section{Considerações finais}

No intervalo de 2013 a 2020, houve um aprofundamento gradativo do discurso de Beyoncé sobre feminismo e as questões raciais. Ainda assim, alguns detalhes pontuais merecem atenção. Inicialmente, não era imaginado que a narrativa heteronormativa perpassaria todas as três escolhas de videoclipes. Em ***Flawless, essa temática era muito mais esperada e explícita, mas por fim, em Brown Skin Girl, a relação dependência do homem foi surpreendente. Mesmo em uma música com o objetivo claro de empoderamento feminino negro, a consequência de ser uma mulher gloriosa é que os homens vão se apaixonar por você.

É preciso ter um olhar crítico sobre tudo que é consumido. É claro que é possível uma artista mainstream expor seus posicionamentos e genuinamente acreditar neles, mas é importante observar a profundidade dos temas tratados e a coerência com toda sua carreira. A visão de feminismo de Beyoncé não liquida a dominação patriarcal. Ainda há uma dependência muito grande dos homens em suas construções narrativas. Mesmo assim, a própria Chimamanda Ngozi Adichie, escritora feminista que possui participação em ***Flawless, relatou em entrevista ao programa Roda Viva que não há feminismo "puro", perfeito, e que todo ser humano está fadado a erros (TV CULTURA, 2021).

Este trabalho foi muito inspirado pelas obras da escritora bell hooks. No entanto, ela já teceu críticas sobre o trabalho de Beyoncé no que diz respeito a uma mercantilização do corpo feminino negro.

Commodities, independentemente do seu assunto, são feitas, produzidas e comercializadas para atrair qualquer e todos os consumidores. A audiência de Beyoncé é o mundo e o mundo dos negócios, e ganhar dinheiro não tem cor, [...] é tudo sobre o corpo, e o corpo como mercadoria. Isto certamente não é radical ou revolucionário. (HOOKS, 2016)

Por outro lado, Joice Berth (2019), autora cujo este trabalho também se apoiou, diz que é importante criar estratégias para fortalecer grupos oprimidos pela existência, em qualquer âmbito. 
Em uma realidade capitalista, é importante criar estratégias de fortalecimento econômico, e tal demanda é fundamental para surgimento de condições favoráveis ao empoderamento. Vale para fortalecimento financeiro, estético, afetivo, dentre tantos que oxigenam a corrida de grupos oprimidos pela existência digna, sobretudo de mulheres negras. (BERTH, 2019, p.91)

Construir um imaginário "descolonizado" a partir do cinema, teatro, música e outros meios torna-se importante para a representatividade. Como afirma Ribeiro (2018, p.135), o empoderamento não pode ser entendido como algo individual, e quando uma mulher se empodera, ela empodera outras. A partir do momento que Beyoncé, uma artista global, produz obras politizadas, mesmo que com críticas e pontos a aprofundar e melhorar, expande-se a reflexão sobre os temas, tanto em seus fãs quanto em outros artistas que, encorajados, podem se posicionar também. A pública tomada de consciência de Beyoncé foi coerente, mas ainda está em construção.

\section{Referências bibliográficas}

ADICHIE, C. N. Ngozi Adichie: Beyoncé's feminism isn't my feminism. Volkskrant, 2016. [Entrevista]. Disponível em: <https://www.volkskrant.nl/cultuur-media/ngozi-adichiebeyonce-s-feminism-isn-t-my-feminism bd0661ea/>. Acessoem 25, maio de 2021. ADICHIE, C. N. We Should All Be Feminists. TEDxEuston, 2012. Disponível em:<https://www.ted.com/talks/chimamanda_ngozi_adichie_we_should_all_be_feminists?lan guage $=$ pt-br $>$. Acesso em: 04, maio de 2021.

ADICHIE, C. N; BEYONCÉ. Flawless. In: BEYONCÉ. Nova Iorque: Parkwood Entertainment and Columbia Records: 2013. Faixa 11 (4 min).

AFROBEATS: gênero renovado é a batida da vez nas pistas londrinas. Vogue, 2015. Disponível em: <https://vogue.globo.com/lifestyle/cultura/noticia/2015/05/afrobeats-genero-renovadoe-batida-da-vez-nas-pistas-londrinas.html>. Acesso em 18, junho de 2021.

ALEXANDER, M. A nova segregação: racismo e encarceramento em massa. São Paulo:

Boitempo, 2017.

BEYONCÉ: Platinum Edition. Nova Iorque: Columbia RecordsandParkwood Entertainment. 2014. Apple Music (2 horas, 55 minutos). Disponível em:

<https://music.apple.com/us/album/beyonc\%C3\%A9-platinum-edition/939775882>. Acesso em 29, maio de 2021.

BERTH, J. Empoderamento. São Paulo: Pólen, 2019.

BEYONCÉ Making The Gift: Documentary 2019. Full Version. American Broadcasting Company (ABC), 16/09/2019. Disponível em: <https://www.youtube.com/watch?v=cZDVZJX4FDQ>. Acesso em 17, junho de 2021. 
BEYONCÉ. "Self-Titled": Part 1. The Visual Album. YouTube.13, dezembro de 2013. Disponível em: <https://www.youtube.com/watch?v=IcN6Ke2V-rQ>. Acesso em 29, maio de 2021.

BEYONCÉ. "Self-Titled": Part 2. Imperfection. YouTube.17, dezembro de 2013. Disponível em: <https://www.youtube.com/watch?v=cIv1z6n3Xxo>. Acesso em 28, maio de 2021. BEYONCÉ. Formation. In: Lemonade. Nova Iorque: Parkwood Entertainment and Columbia Records: 2016. Faixa 12 (4 min 48).

BEYONCÉ, Blue Ivy, Saint Jhn, WizKid. Brown Skin Girl. In: The Lion King: The Gift. Nova Iorque: ParkwoodEntertainmentand Columbia Records: 2019. Faixa 8 (4 min 08).

CHIMAMANDA NgoziAdichie "decepcionada" com o sucesso de música de Beyoncé. Rede Angola, 2016. Disponível em: <http://m.redeangola.info/chimamanda-ngozi-adichiedecepcionada-com-o-sucesso-de-musica-de-beyonce/>. Acesso em 25, maio de 2021. CORRÊA, A. Em meio a passagem do furacão Laura, Nova Orleans lembra 15 anos do Katrina e enfrenta devastação do coronavírus. BBC News Brasil, 2020. Disponível em:

<https://www.bbc.com/portuguese/internacional-53944395>. Acesso em 14, junho de 2021. FOR Beyoncé, Creativity Is the Ultimate Power. ELLE. 2019. Disponível em: <https://www.elle.com/culture/celebrities/a29999871/beyonce-ivy-park-adidasinterview/https://www.elle.com/culture/celebrities/a29999871/beyonce-ivy-park-adidasinterview/>. Acesso em 03, abril de 2021.

HARRISON, C. The visual album as a hybrid art-form: A case study of traditional, personal, and allusive narratives in Beyoncé. Master's Thesis (Master of Arts in Visual Culture) - Lunds University. Sweden, p. 72, 2014. Disponível em: <https://lup.lub.lu.se/studentpapers/search/publication/4446946>. Acesso em: 10, outubro de 2020. HOOKS, B. Mover-se Além da Dor. 12, maio de 2016. Disponível em: <https://www.geledes.org.br/mover-se-alem-da-dor-bell-hooks/>. Acesso em 20, junho de 2021.

HOOKS, B. Mulheres negras: moldando a teoria feminista. Rev. Bras. Ciênc. Polít. [online]. 2015, n.16, p.193-210. Disponível em: <DOI: https://doi.org/10.1590/0103335220151608>. Acesso em 27, maio de 2021.

KARNAL, L et al. História dos Estados Unidos: das origens ao século XXI. São Paulo: Contexto, 2007.

LESSA, R. ChimamandaNgoziAdichie explica o que realmente disse sobre Beyoncé em crítica ao jornalismo sensacionalista. Geledés, 2017. Disponível em:

<https://www.geledes.org.br/chimamanda-ngozi-adichie-explica-o-que-realmente-dissesobre-beyonce-em-critica-ao-jornalismo-sensacionalista/>. Acesso em 25, maio de 2021. 
NAVARRO, R. Quem foram os Panteras Negras. Super Interessante, 2019. Disponível em: <https://super.abril.com.br/mundo-estranho/quem-foram-os-panteras-negras/>. Acesso em 12 , junho de 2021.

O que é liveaction? FilmeFeed, 2020. Disponível em:

<https://filmefeed.telecineplay.com.br/o-que-e-live-action/p>. Acesso em 16, julho de 2020. O que foi o movimento punk? Super Interessante, 2018. Disponível em:

<https://super.abril.com.br/mundo-estranho/o-que-foi-o-movimento-punk/>. Acesso em 29, maio de 2020.

OLIVEIRA, M. RExistência: "O afrofuturismo imagina futuros possíveis, com olhar sobre a ancestralidade e o presente". Socialismo Criativo. 2021. Disponível em:

<https://www.socialismocriativo.com.br/rexistencia-o-afrofuturismo-imagina-futurospossiveis-com-olhar-sobre-a-ancestralidade-e-opresente/\# : :text=K\%C3\%AAnia\%20resume\%20que\%200\%20afrofuturismo,\%2C\%20tanto \%20africana\%20quanto\%20diasp\%C3\%B3rica\%E2\%80\%9D>. Acesso em 30, abril de 2021. RIBEIRO, D. Quem tem medo do feminismo negro? São Paulo: Companhia das Letras, 2018.

RODA Viva com ChimamandaNgoziAdichie. TV Cultura. 2021.Disponível em: <https://www.youtube.com/watch?v=pxe92zWOotE>. Acesso em 14, junho de 2021. SANTIAGO, S. O significado de Lemonade: Parte 1 (Análise) - Beyoncé. Canal Spartakus. 20, agosto de 2020. Disponível em:

<https://www.youtube.com/watch?v=ryO8L37_MjU\&t=195s>. Acesso em: 03, maio de 2021. VECCHIA, L. Expandindo as Fronteiras do Álbum Visual: O Caso Lemonadede Beyoncé Knowles. In: XXII Congresso de Ciências da Comunicação na Região Sudeste. Volta Redonda: 2017. Disponível em: <https://portalintercom.org.br/anais/sudeste2017/resumos/R58-06321.pdf>. Acesso em 20, maio de 2021.

WOMACK, Y. Afrofuturism: The World of Black Sci-Fi and Fantasy Culture. Chicago: Lawrence Hill Books, 2013. 